\title{
Peroral Endoscopic Myotomy with Water Pump-Assisted Submucosal Tunnel Creation
}

\author{
José Pedro Rodrigues Pedro Barreiro lala Carina Liliana Carvalho \\ Pedro Figueiredo Cristina Chagas
}

Serviço de Gastrenterologia, Centro Hospitalar de Lisboa Ocidental, Lisbon, Portugal

\section{Keywords}

Achalasia - Peroral endoscopic myotomy - Water pump .

Endoscopy · Dysphagia

\section{Miotomia endoscópica peroral com criação do túnel na submucosa assistida por bomba de água}

\section{Palavras Chave}

Acalásia - Miotomia endoscopica peroral · Bomba de água Endoscopia · Disfagia

Achalasia is an idiopathic motor disorder of the esophagus characterized by impaired lower esophageal sphincter relaxation and loss of esophageal peristalsis, which results in the classic presentation of dysphagia to solids and liquids associated with regurgitation of food and saliva [1]. From the available treatment options, endoscopic balloon dilatation and laparoscopic Heller myotomy have been the most frequently used. More recently, peroral endoscopic myotomy (POEM) was developed in Japan. This endoscopic technique requires the creation of a submucosal tunnel as an operating space to access the circular muscle layer for performance of the myotomy [2]. Short-term results from the available series are promising when compared to the alternative approaches. However, procedure length still varies greatly, and the use of devices has also

\section{KARGER}

E-Mail karger@karger.com www.karger.com/pjg
(C) 2018 Sociedade Portuguesa de Gastrenterologia Published by S. Karger AG, Basel

Karger

0 pen access

This article is licensed under the Creative Commons AttributionNonCommercial-NoDerivatives 4.0 International License (CC BYNC-ND) (http://www.karger.com/Services/OpenAccessLicense). Usage and distribution for commercial purposes as well as any distribution of modified material requires written permission. not been standardized. Water jet-assisted POEM, which uses needleless submucosal injections to create a submucosal fluid cushion (usually using a hybrid knife), has been demonstrated to significantly decrease POEM procedure length and to facilitate reinjection, contributing to a lower rate of intraprocedural bleeding [3]. A modified technique with a method of injecting saline mixed with indigo car-

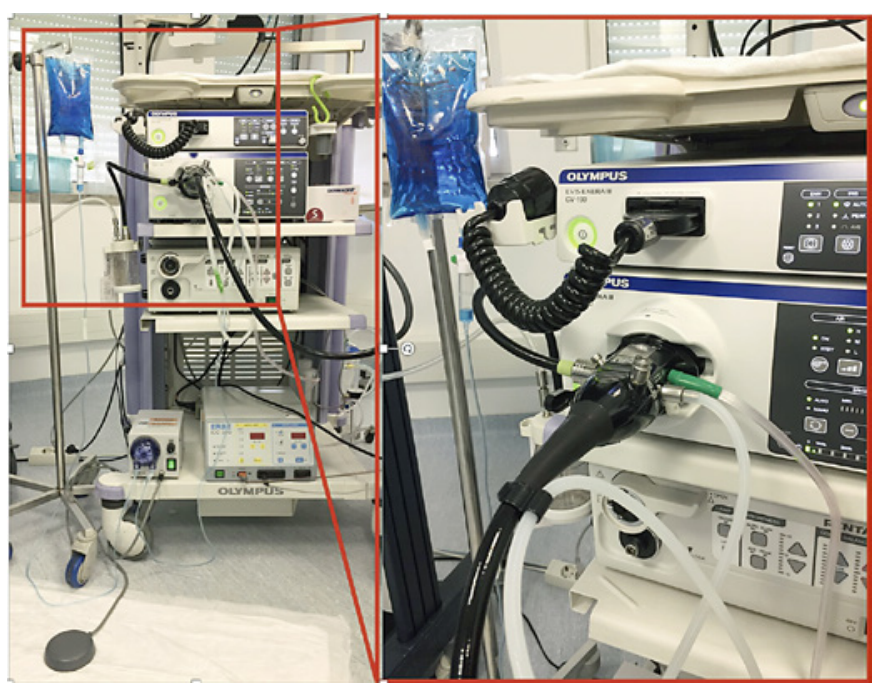

Fig. 1. Equipment for jet injection of dyed saline. Water pump connected to a flask with solution to inject into the submucosa (Voluven ${ }^{\circledR}$ and indigo carmine). 

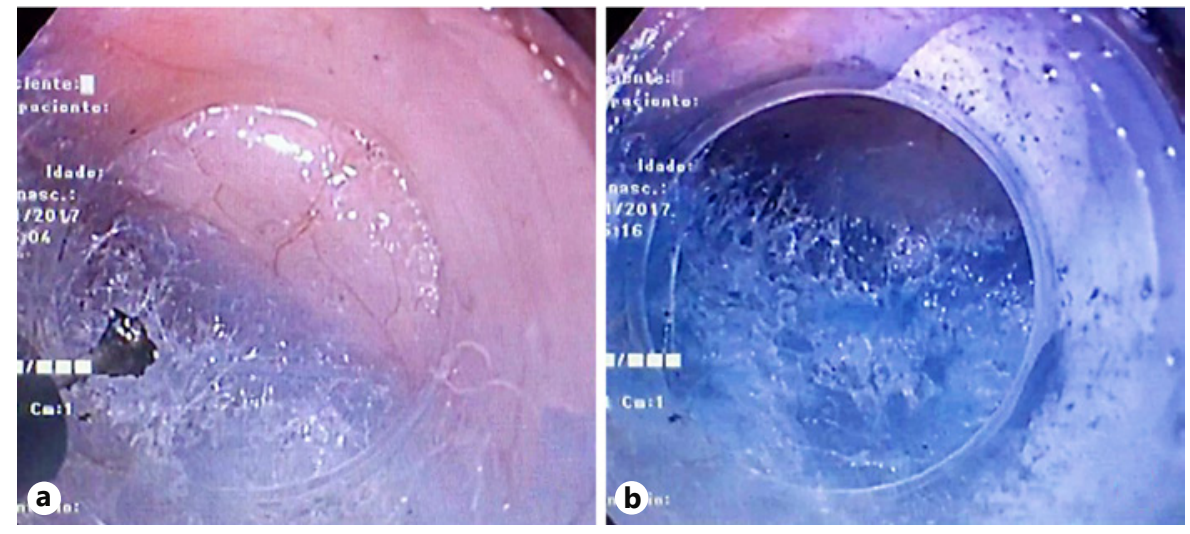

Fig. 2. Submucosal tunnel before (a) and after (b) jet injection of dyed saline.

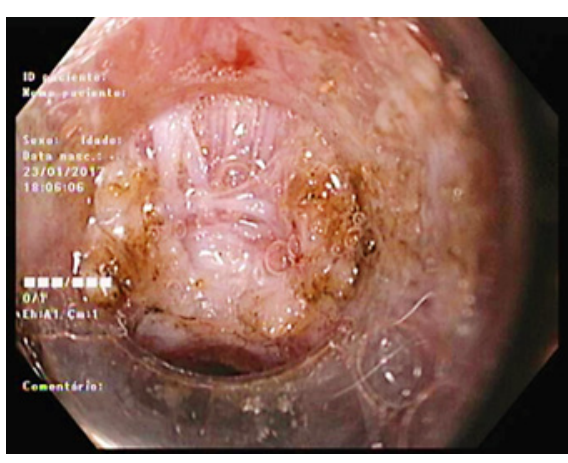

Fig. 3. Esophageal circular muscular layer myotomy. mine through an integrated water jet channel was subsequently described. Using the water pump, repeated jet injection of dyed saline is performed whenever the submucosal plane becomes unclear. This technique is simple, feasible, and may make POEM easier and more efficient than the standard method [4]. We present a case where this technique was performed.

A 35-year-old male patient presented with dysphagia, which started several months before (Eckardt score of 6 at presentation), and was diagnosed with type I achalasia. Following a discussion of all therapeutic options with the patient, POEM was decided on, and a written informed consent was obtained. The procedure was performed under general anesthesia, with $\mathrm{CO}_{2}$ insufflation using the Triangle Knife (Olympus) and an Olympus gastroscope (GIFHQ190) connected to the water pump. The water pump was connected to a bag with solution to inject into the submucosa (Voluven ${ }^{\circledR}$ and indigo carmine) (Fig. 1). An anterior approach was performed with incision in the esophageal mucosa at 2-3 o'clock, followed by a submucosal tunnel creation ( $17 \mathrm{~cm}$ extension). During tunnel creation, the water pump was activated whenever necessary with good submucosal expansion without the necessity of changing the knife for the needle/catheter spray throughout the procedure (Fig. 2). After tunnel creation, myotomy was performed (approximately $12 \mathrm{~cm}$ extension) followed by mucosal closure with clips (Fig. 3). The procedure was performed in $90 \mathrm{~min}$. Considering that our clinical experience is still in an early stage, this case was treated faster than the mean procedural time described in this setting (140 $\mathrm{min})$ [5]. The patient remained hospitalized for $48 \mathrm{~h}$ without complications. Four months after the procedure, the patient remains asymptomatic (Eckardt score 0 ). To our knowledge, this is the first report showing endoscopic treatment of achalasia by POEM with water pump-assisted submucosal tunnel creation in a European center.

\section{Statement of Ethics}

Written informed consent was obtained from the patient.

\section{Disclosure Statement}

The authors report no potential conflict of interest.

\section{Author Contributions}

All authors have seen and approved the manuscript being submitted. All authors listed contributed significantly to the work.

\section{References}

1 Vaezi M, Paldofino J, Vela M: Diagnosis and management of achalasia. Am J Gastroenterol 2013;108:1238-1249.

- 2 Inoue H, Minami H, Kobayashi Y, Sato Y, Kaga M, Suzuki M, Satodate $\mathrm{H}$, Odaka N, Ito H, Kudu S: Peroral endoscopic myotomy (POEM) for esophageal achalasia. Endoscopy 2010;42:265-271.

-3 Cai MY, Zhou PH, Yao LQ, Xu MD, Zhong YS, Li QL, Chen WF, Hu JW, Cui Z, Zhu BQ: Peroral endoscopic myotomy for idiopathic achalasia: randomized comparison of water-jet assisted versus conventional dissection technique. Surg Endosc 2014;28:1158-1165.

-4 Khashab MA, Messallam AA, Saxena P, Kumbhari V, Ricourt E, Aguila G, Roland BC, Stein E, Nandwani M, Inoue H, Clarke JO: Jet injection of dyed saline facilitates efficient peroral endoscopic myotomy. Endoscopy 2014;46:298-301.

5 Hong D, Pescarus R, Khan R, Ambrosini L, Anvari M, Cadeddu M: Early clinical experience with the POEM procedure for achalasia. Can J Surg 2015;58:389-393. 